\title{
O USO DA TERAPIA LASER DE BAIXA INTENSIDADE APÓS EXODONTIA DE TERCEIROS MOLARES: REVISÃO DE LITERATURA
}

\author{
Amanda Affonsêca Pedreira Mestranda em Estomatologia pela Escola \\ Bahiana de Medicina e Saúde Pública.
}

Maíra Sá Graduanda em Odontologia pela Escola Bahiana de Medicina e Saúde Pública.

\author{
Alena Ribeiro Alves Peixoto Medrado Mestrado e doutorado em Patologia Humana \\ pela Fundação Oswaldo Cruz/ UFBA. \\ Professora da Escola Bahiana de Medicina e \\ Saúde Pública.
}

\begin{abstract}
Resumo
A exodontia é um procedimento odontológico que envolve trauma aos ossos e tecidos moles. A gravidade da intervenção, a localização das unidades dentárias, a textura tecidual e o grau de destruição óssea são váriaveis que interferem na presença ou ausência de efeitos pós-operatórios deletérios, em particular no que diz respeito à exodontia de terceiros molares. A terapia laser de baixa intensidade (LLLT) tem sido usada clinicamente para acelerar a cicatrização de feridas e controlar a dor. No entanto, embora a laserterapia passa a ser indicada após exodontias de terceiros molares, seu uso tem sido raramente prescrito. O objetivo desse artigo é fazer uma revisão da literatura sobre o uso da laserterapia durante o período pós-operatório da remoção cirúrgica de terceiros molares.
\end{abstract}

Palavras-chave: Cirurgia oral; Laserterapia; Dor; Complicações pós-operatória e terceiro molar.

\section{THE USE OF LOW-LEVEL-LASER THERAPY AFTER THIRD MOLARS EXTRACTION: A LITERATURE REVIEW}

\begin{abstract}
Dental extraction is a procedure involving bones and soft tissues trauma. The intervention severity, dental units location, tissue consistency and the degree of bone destruction are variables that influences the presence or absence of postoperative deleterious effects, particularly regarding the third molar extraction. The low-levellaser therapy (LLLT) has been used clinically to accelerate wound healing and pain control. However, while laser therapy is now indicated after extraction of third molars, its use has been rarely prescribed. This article aims to perform a literature review on the use of laser therapy during the third molars surgical removal postoperative phase.
\end{abstract}

Keywords: Oral Surgery; Laser therapy; Pain; Postoperative complications and molar third.

\section{Introdução}

O laser é um dispositivo composto por substâncias variadas, as quais uma vez excitadas por uma fonte de energia, produzem um feixe de luz monocromática. ${ }^{(1,2)}$ Trata-se de uma modalidade de radiação eletromagnética. De acordo com a potência de emissão, a radiação laser é classificada em alta, média e baixa intensidade. ${ }^{(3)}$ Em relação à utilidade clínica, o laser pode ser classificado em dois grandes grupos: lasers de alta potência ou cirúrgicos, apresentando efeitos térmicos, propriedades de corte, vaporização e hemostasia, e 
lasers de baixa potência ou terapêuticos, com propriedades analgésicas, antiinflamatórias e de bioestimulação. ${ }^{(4,5)}$

Para a abordagem terapêutica do laser, também conhecida por laserterapia, os tipos mais utilizados variam de acordo com a substância que compõe a cavidade ressonante do aparelho. Podem constituir um meio gasoso, a exemplo do laser de Hélio-néon (HeNe) com comprimento de onda de $632,8 \mathrm{~nm}$. O meio laser pode ser representado também por um diodo semicondutor composto por polos positivo e negativo, respectivamente. Nesta categoria estão incluídos o laser de Arsenieto de Gálio e Alumínio (GaAlAs) com comprimento de onda da ordem de 620 a 830 nm, Arsenieto de Gálio (GaAs) com 830 a 904 nm e o Fosfeto de ÍndioGálio-Alumínio (InGaAlP) com $685 \mathrm{~nm}^{2}$.

Os lasers de baixa intensidade são utilizados como agentes terapêuticos após o tratamento convencional, evidenciando propriedades antiinflamatórias, analgésicas e de aceleração da cicatrização de feridas, o que pode propiciar um pós-operatório mais confortável ao paciente, com redução do uso de medicamentos ${ }^{6}$. Ele não possui um efeito diretamente curativo. No entanto, as propriedades supracitadas proporcionam uma atenuação do quadro clínico do paciente durante o período pós-operatório com redução do edema intersticial e diminuição da sintomatologia dolorosa. As análises histopatológicas dos tecidos irradiados comumente exibem sinais de reparação tecidual da região lesada mediante o processo de bioestimulação celular. ${ }^{(7)}$

Em vista disso, o laser apresenta-se como uma alternativa terapêutica para os casos clínicos e cirúrgicos nos quais ocorra inflamação, dor e que necessitem de um estímulo a mais para a regeneração e reparo tecidual, independente do tecido em questão. A remoção cirúrgica de terceiros molares representa uma indicação precisa para a utilização da laserterapia. Nesta situação, em particular, o organismo responde ao trauma cirúrgico através de fenômenos vasculares e celulares deflagrados por mediadores químicos a fim de cicatrizar o tecido que foi danificado. ${ }^{(8)}$ Paradoxalmente, estes fenômenos também contribuem para o desenvolvimento de complicações pós-operatórias muito comuns as quais incluem o edema, a dor e o trismo. ${ }^{(9,10)}$ Por serem consequências indesejáveis e muito frequentes, cada dia tem se desenvolvido mais estudos visando amenizar ou, se possível até mesmo erradicar, estas complicações pós-operatórias.

O objetivo desse artigo é fazer uma revisão de literatura sobre o uso da laserterapia durante o período pós-operatório da remoção cirúrgica de terceiros molares. Objetiva, adicionalmente, relatar a sua eficácia na redução dos parâmetros clínicos utilizados na 
avaliação dos fatores complicadores mais comuns a este procedimento cirúrgico, a saber, edema, dor e trismo.

\section{Revisão discutida da literatura}

A exodontia de terceiros molares nos dias atuais tem sido um procedimento bastante realizado na clínica odontológica, principalmente com finalidade ortodôntica. A principal indicação para esse procedimento se dá quando estes dentes apresentam-se retidos. Os dentes retidos recebem esta denominação em função de ultrapassarem a época de sua erupção, seja por razões mecânicas ou patológicas, mantendo ou não comunicação com a cavidade bucal. ${ }^{(11)}$ A freqüência do número de dentes retidos tem aumentado na população devido principalmente a um crescimento maior da calota craniana em detrimento dos maxilares e a uma dieta cada vez menos exigente do aparelho estomatognático. Alie-se a estes fatos, a concepção da prática odontológica com ênfase para a prevenção, na qual o número de extrações na infância e adolescência tem diminuído significativamente. Desta forma, inicia-se a idade adulta com todos os elementos dentários na arcada, o que pode, via de regra gerar falta de espaço na maxila e na mandíbula. ${ }^{(12)}$

Apesar da cirurgia de terceiros molares estar se tornando cada vez mais rotineira, ela apresenta grandes desafios a serem superados. As dificuldades mais relatadas na literatura incluem uma íntima relação com estruturas anatômicas nobres, a angulação das coroas dos dentes inclusos, as impacções, além das complicações da cirurgia propriamente dita que podem ser deflagradas no momento da ostectomia, da odontossecção e da remoção destes dentes. ${ }^{(13,14)}$ Ademais, a extração de terceiros molares, inclusos ou não, geralmente causa trauma cirúrgico significativo e desencadeia uma resposta imunopatológica inata de defesa - a inflamação. $^{(8)}$ O trauma envolve ossos e tecidos moles. Sendo a face intensamente vascularizada, e os tecidos moles constituídos por tecido conjuntivo frouxo, há grande propensão à formação de edema e, por consequência, o aparecimento de outras manifestações pós-operatórias indesejáveis, como o trismo e a dor. ${ }^{(7)}$

Entre os acidentes e complicações mais comuns após a remoção cirúrgica de terceiros molares, encontram-se as hemorragias, alveolites, dor, edema e trismo, injúria ao nervo alveolar inferior, infecções abrangendo espaços fasciais, injúrias em dentes adjacentes, fratura óssea da tuberosidade maxilar e/ou da mandíbula, comunicações buco sinusais, problemas periodontais em dentes adjacentes e deslocamento de dentes para regiões anatômicas nobres ${ }^{15}$. 
De acordo com Chukwuneke e Onyejiaka (2007), ${ }^{(16)}$ dor, edema e trismo são as principais causas do desconforto pós-operatório, afetando a qualidade de vida dos pacientes.

O trismo refere-se à limitação da abertura de boca e em muitos casos apresenta-se associado às intervenções orais cirúrgicas realizadas na região do ramo e o ângulo mandibular. A sua presença está diretamente relacionada à gravidade da intervenção, consitência tecidual e destruição ossea. A posição dos terceiros molares inferiores, especialmente os impactados, remoções complicadas, bem como as características de circulação na região tornam a presença do trismo mais frequente após a remoção desses dentes. ${ }^{(16)}$ Em tais casos, o trismo é geralmente associado com edema, e dor de longa duração e alta intensidade. ${ }^{(17,18)}$

A duração do trismo depende da destruição tecidual local e da gravidade da intervenção cirúrgica, sendo que geralmente, desaparece entre 5 a 7 dias. A terapia indicada nesses casos é voltada para a redução do edema, o qual apresenta-se intimamente associado com o trismo. O tratamento inclui a administração pré e pós-operatória de corticosteróides no intuito de reduzir o extravasamento de linfa e plasma proveniente dos vasos sanguíneos e, consequentemente, o acúmulo de líquido no interstício. São indicados anti-inflamatórios não esteróides (AINEs) no pós-operatório, bem como as compressas de gelo e analgésicos ${ }^{19,20}$.

A dor que se instala no paciente após a cirurgia de terceiros molares apresenta-se em maior intensidade nas 3 e 5 horas iniciais, ao passo que o edema alcança sua expressão máxima entre as primeiras 24 e 48 horas do período pós-operatório ${ }^{12}$. Várias terapias têm sido descritas para o controle da morbidade pós-operatória da cirurgia dentoalveolar a exemplo do uso de anti-inflamatórios esteróides, dos AINEs, do laser de baixa intensidade e de drenos intrabucais $^{21}$. Os anti-inflamatórios não-esteróides agem através do bloqueio da enzima ciclooxigenase, inibindo a síntese de prostaglandinas e, desta forma, reduzem os sinais cardeais da inflamação. Um dos principais AINEs utilizados na cirurgia bucal é o diclofenaco de sódio. Esse fármaco é um derivado do ácido heteroarilacético e possui efeito analgésico, antipirético e anti-inflamatório. ${ }^{(22)}$

Existem muitas pesquisas a cerca da utilização do laser na Odontologia e o seu uso terapêutico tem sido cada vez mais estudado. Resultados favoráveis, oriundos da utilização desta modalidade terapêutica, tem sido descritos na literatura. De acordo com Genovese (2000), ${ }^{(3)}$ os efeitos biológicos que o laser de baixa potência provoca nos tecidos consistem em energia luminosa, a qual se deposita sobre os mesmos e se transforma em energia vital, 
produzindo, então, efeitos primários (diretos), secundários (indiretos) e terapêuticos gerais. Desta forma, alcançam-se benefícios de natureza analgésica, anti-inflamatória e cicatrizante.

A terapia laser de baixa intensidade geralmente apresenta comprimento de onda entre 600 a 900 nanômetros que apresentam boa transmissão na pele e mucosas. Entre estes comprimentos de onda no espectro vermelho e infravermelho próximo, estão as radiações que produzem efeitos terapêuticos, como bioestimulação, proliferação, diferenciação e síntese de proteínas. ${ }^{(23)}$ Quando a luz laser interage com as células e tecidos na dose adequada, certas funções celulares podem ser estimuladas, como a ativação de linfócitos e mastócitos, aumento na produção de ATP mitocondrial e proliferação de vários tipos de células. Assim a fototerapia pela luz laser destaca-se como uma alternativa terapêutica bioestimuladora para o reparo tecidual, aumentando a circulação local, a proliferação celular e a síntese de colágeno. $^{(24)}$

As ações anti-inflamatórias e antiedematosas exercidas pelo laser ocorrem mediante a aceleração da microcirculação, que resulta em alterações na pressão hidrostática capilar e favorecem a reabsorção do edema e eliminação do acúmulo de metabólitos intermediários. ${ }^{(25)}$ Ainda em nível vascular, a laserterapia estimula a proliferação das células endoteliais, resultando na formação de numerosos vasos sanguíneos que exibem relaxamento da musculatura vascular lisa. ${ }^{(26)}$

Conforme já citado, o processo de bioestimulação promovido pelo laser de baixa potência desencadeia os efeitos terapêuticos antiálgico, antinflamatório, antiedematoso e cicatrizante, proporcionando ao paciente a otimização do conforto e o bem-estar tão almejados no tratamento odontológico. ${ }^{(27)}$ Assim, segundo Walsh ${ }^{(26)}$ o laser desempenharia um importante papel no reparo alveolar após extração dental, uma vez que exerce efeitos pronunciados em cultura de osteoblastos, influenciando os processos de proliferação, diferenciação e calcificação.

Muitos estudos observaram que a reparação alveolar é acelerada quando se faz a utilização da laserterapia, porém existem ainda controvérsias em relação ao tipo de aparelho utilizado, ao tempo de exposição, ao comprimento de onda e o número de aplicações a serem realizadas. Garcia et al. (2000), ${ }^{(28)}$ realizaram um estudo histológico em ratos para avaliar a influência do número de aplicações de laser sobre o reparo alveolar. Sessenta e quatro ratos foram submetidos a exodontia do incisivo superior do lado direito e divididos em quatro grupos: o grupo I (Controle) não recebeu aplicação de laser, o II recebeu uma aplicação imediatamente após a exodontia, o III foi submetido às aplicações imediatamente e 24 horas 
após a cirurgia e o IV recebeu aplicação imediata, 24 horas e 48 horas após a cirurgia. $\mathrm{O}$ aparelho de raio laser utilizado foi o CAVITY-D1-UP [Space Laser] de Arsênio e Gálio com emissão infra-vermelha e comprimento de onda de $904 \mathrm{~nm}$. Os ratos foram sacrificados e os tecidos foram encaminhados à análise histológica. Dessa forma, foi possível observar que as feridas dos grupos II, III e IV obtiveram organização mais rápida do coágulo sanguíneo, intensa proliferação fibroblástica, formação óssea mais precoce e intensa, e consequentemente, uma cicatrização mais rápida da ferida em relação ao grupo I. Observouse também que o aumento do número de aplicações foi diretamente proporcional à aceleração do processo de reparo alveolar, sem que tenha sido esclarecida, no entanto, a relação entre esses dois fatores.

Tem sido associado ao uso do laser, antinflamatórios. Em vista disso, Prockt et al. $(2009){ }^{(8)}$ realizaram um estudo para avaliar a eficácia do laser de baixa intensidade, do diclofenaco de sódio e de um placebo no controle das morbidades pós-operatórias associadas à exodontia de terceiros molares. Foram realizadas exodontias de 36 terceiros molares inferiores e os pacientes foram divididos em 3 grupos: o grupo 1 (fizeram uso do diclofenaco e falsa irradiação laser), o 2 (usaram placebo e irradiação laser) e o 3 (uso de placebo e falsa irradiação laser). O laser aplicado foi o Photon Laser III [DCM] de Arsenieto de gálio e alumínio com $100 \mathrm{~mW}$ e $808 \mathrm{~nm}$. Os resultados obtidos no estudo revelaram uma maior redução do edema no grupo 1. Já o grupo laser apresentou uma diminuição do trismo e da dor, porem esses resultados apresentaram-se sem relevância estatística devido ao tamanho da amostra utilizada. Dessa forma, a metodologia empregada no estudo não pôde comprovar a eficácia nem do laser, nem do diclofenaco na redução dos sintomas pós-operatórios.

O estudo realizado por Jovanovic et al. (1998), ${ }^{(17)}$ avaliou a eficácia do laser de baixa intensidade no tratamento do trismo após exodontia de terceiros molares inferiores através do grupo controle, submetido à tratamento medicamentoso e físico, e o experimental, que teve o laser aplicado no pós-operatório e três dias depois, além do tratamento convencional. O laser utilizado foi o GaAlAs "MILS 94" com potência de saída de $10 \mathrm{~mW}$ e comprimento de onda de $670 \mathrm{~nm}$. Foram realizadas medidas da abertura de boca antes da cirurgia e três dias depois, estabelecendo o grau de abertura de boca através do coeficiênte de trismo pós-operatório. Foi observado que o trismo nos pacientes tratados com laser foi menos expressivo do que naqueles que não foram submetidos a irradiação. Os autores concluiram que o laser representa um meio complementar totalmente seguro de tratamento pós-operatório e muito eficaz na redução do trismo. 
Uma outra investigação, conduzida por Filho et al. (2008), ${ }^{(29)}$ utilizou a amostra de 13 pacientes submetidos à exodontia de terceiros molares inferiores bilaterais com o objetivo de avaliar o efeito do laser terapêutico na diminuição de complicações pós-operatórias como dor, edema e trismo. Em um dos lados do paciente foi aplicado laser de arseneto de gálio de 904nm, na região extra e intra-oral no pré e pós-operatório. No outro lado, realizaram-se aplicações com placebo. Concluiu-se com esse estudo que a laserterapia foi efetiva para diminuição da dor e do trismo no pós-operatório de extrações de terceiros molares inferiores inclusos, entretanto não houve ação sobre o edema.

\section{Considerações finais}

Devido à existência de muitos estudos que afirmam ser o laser indicado para diminuir as complicações pós-operatórias e a maioria deles não chegar a um acordo quanto ao comprimento de onda e número de aplicações, há protocolos muito diversos o que torna difícil a comparação entre os estudos. Dessa forma, é importante realizar novas investigações com o objetivo de uniformizar a dosimetria utilizada e determinar a indicação correta da laserterapia de baixa intensidade.

\section{Referências}

1. Lins RDAU, Dantas EM, Lucena KCR, Catão MHCV, Granville-Garcia AF, Carvalho Neto LG. Efeitos bioestimulantes do laser de baixa potência no processo de reparo. An Bras Dermatol. 2010; 85(6): 849-55.

2. Prockt AP, Takahashi A, Pagnoncelli RM. Uso de Terapia com Laser de Baixa Intensidade na Cirurgia Bucomaxilofacial. Revista Portuguesa de Estomatologia, Medicina Dentária e Cirurgia Maxilofacial 2008; 49(4).

3. Genovese WJ. Laser de baixa intensidade: Aplicações Terapêuticas em Odontologia. São Paulo: Lovise; 2000.

4. Barros FC, Antunes SA, Figueredo CMS, Fischer RG. Laser de baixa intensidade na cicatrização periodontal. R Ci Med Biol. 2008; 7: 85-89.

5. Silva EM, Gomes SP, Ulbrich LM, Giovanini AF. Avaliação histológica da laserterapia de baixa intensidade na cicatrização de tecidos epitelial, conjuntivo e osseo: estudo experimental em ratos. Rev Sul-Bras Odontol. 2007; 4: 29-35.

6. Damante CA, Marques MM, Micheli GD. Terapia com laser em baixa intensidade na cicatrização de feridas - revisão de literatura. RFO. 2008 Set/Dez; 13(3): 88-93. 
7. Maluf AP, Ughini GC, Maluf RP, Pagnoncelli RM. Utilização de laser terapêutico em exodontia de terceiros molares inferiores. RGO. 2006; 54: 182-4.

8. Prockt AP, Wagner JCBW, Gerhardt EL, Volkweis MR. O uso do diclofenaco sódico e o laser de baixa intensidade após a cirurgia de terceiros molares. Rev. Cir. Traumatol. BucoMaxilo-fac., Camaragibe. 2009 Jul/Set; 9(3): 113-120.

9. Marzola C. Inclusão dental. São Paulo: Pancast; 1995.

10. Cavalcanti MG, Gouveia FMV, Laureano-Filho JR. A influência da crioterapia na redução do edema, dor e trismo no pós-cirúrgico de terceiros molares inferiores impactados. Recife, 2002. [Monografia - Faculdade de Odontologia da Universidade Federal de Pernambuco].

11. Zorzetto DLG, Marzola C, Toledo JL, Pastori CM, Lobo SE. Cirurgia de terceiros molares inferiores retidos. RGO. $2000 \mathrm{Abr} / \mathrm{Maio} / \mathrm{Jun} ; 2$ : 102-8.

12. Petterson LJ. Cirurgia oral e maxilofacial contemporânea. 4. ed. Rio de Janeiro: Elsevier; 2005.

13. Moreira, JGC. Cirurgia dos dentes retidos. In: Colombini, NEP. Cirurgia maxilofacial: cirurgia do terço inferior da face. São Paulo: Pancast, 1991.

14. Felix, VB. Implante de Alveosan ${ }^{\circledR}$ e de Anaseptil Pó ${ }^{\circledR}$ associado ao Eugenol em alvéolos dentais após a exodontia. Estudo microscópico em ratos. Marília, 2006. [Dissertação Faculdade de Ciências Odontológicas da Universidade de Marília.

15. Goldberg, MH.; Nemarick, AN.; Marco, WP. Complications after mandibular third molar surgery:a statistical analysis of 500 consecutive procedures in private practice. J Am Dent Assoc 1985 111: 277.

16. Chukwuneke FN, Onyejiaka N. Management of postoperative morbidity after third molar surgery: a review of the literature. Niger J Med. 2007; 16(2): 107-12.

17. Jovanovic G. Low power laser effect on wound healing after tooth extraction and mouth surgery. Ph.D. Thesis, Nis, 1998.

18. Carillo JS, Calatayud J, Manso FJ, Barberia E, Martinez JM, Donaldo M. A randomized double-blind clinical trial on the effectiveness of helium-neon laser in the prevention of pain, swelling and trismus after removal of impacted third molar. Int Dent J 1990; 40: 31-36.

19. Roynesdal AK, Bjornlad T, Barkvoll P, Haanaes HR. The Effects of soft-laser application on postoperative pain and swelling. Int J Oral Maxxillofac Surg 1993; 22: 242-245.

20. Jovanovic G, Buric N, Kesic Lj. Effect of low power laser on postoperative trismus. Medicine and Biology 2004; 11(3): 136-138.

21. Aoki T, Yamaguchi H, Naito H, Shiiki K, Izawa K, Ota Y, et al. Premedication with cyclooxygenase-2 inhibitor meloxicam reduced postoperative pain in patients after oral surgery. Int J Oral Maxillofac Surg 2006; 35(7): 613-7. 
22. Burke A, Smyth E, FitzGerald GA. Analgésico-antipiréticos; farmacoterapia da gota. In: Brunton LL, Lazo JS, Parker KL. Goodman \& Gilman: As bases farmacológicas da terapêutica. $11^{\text {a }}$ ed. Rio de Janeiro: McGraw-Hill; 2007: 601-38.

23. Werneck CE, Genovese WJ, Bordini PJ, Melo MS. Efeitos do laser terapêutico sobre sistemas biológicos - Revisão de literatura. Rev Bras. Implant. 2002; 8(3): 13-5.

24. Rocha Junior AM, Vieira B.J, Andrade LCF, Monteiro A. Effects of low-level laser therapy on the progress of wound healing in humans: the contribution of in vitro and in vivo experimental studies. J Vasc Bras.2007; 6: 258-66.

25. Camelo FP. Avaliação clinica do efeito da irradiação pós-operatório do laser de baixa intensidade na cicatrização de gengivoplastias em humanos. Natal, 2007. [Dissertação Faculdade de Odontologia da Universidade Federal do Rio Grande do Norte].

26. Walsh LJ. The current status of low level laser therapy in dentistry. Part 1. Soft tissue applications. Austr Dental J. 1997; 42: 247-54.

27. Soares JMF. Laserterapia no mecanismo da dor. Recife, 2002. [Monografia - Faculdade de Odontologia da Universidade de Pernambuco].

28. Garcia GV, Theodoro L, Colman SL, Fonseca GR, Okamoto T. Influência do número de aplicações de raio laser de bioestimulação sobre a reparação de feridas de extração dentária. Estudo histológico em ratos. Rev Fac Odontol Lins. 2000 jan/dez; 12(1/2): 29-37.

29 Filho JRL, Camargo IB, Firmo ACB, Silva, EDO. A influência do laser de baixa intensidade na redução de edema, dor e trismo no pós-operatório de cirurgia de terceiros molares inferiores inclusos: resultado preliminar com 13 casos. Rev. Cir. Traumatol. BucoMaxilo-fac., Camaragibe. 2008 Jan/Mar; 8(1): 47-56. 